\title{
Сюлейман Демирхан
}

\section{ОСНОВНЫЕ КОНЦЕПТУАЛЬНЫЕ ПОДХОДЫ К ФОРМИРОВАНИЮ ТОЛЕРАНТНОСТИ В МЕЖКУЛЬТУРНОЙ СРЕДЕ}

\begin{abstract}
В статье исследуется понятие «толерантность»в веловеческой среде, рассматриваются его этапы формирования и развития: от значения «смирение», «аскетизм», «веротерпимость» до «уважение, правильное понимание и принятие других культур, взглядов, способов самовыражения и проявления личностной индивидуальности». Чтобы любое современное общество успешно развивалось и чтобы такие глобальные проблемы, как религиозная дискриминация, национализм, расизм, не имели иирокого распространения в мире, важно умение всех и каждого адаптироваться к быстро меняющейся сочиальной среде, проявлять толерантность. В будущем мировое общество перейдет к новым вариантам и моделям общей толерантной культуры.

Ключевые слова: толерантность, терпимость, культура, точка зрения, многонациональная окружающая среда.
\end{abstract}

Понятие «толерантность» - это социологический термин, обозначающий терпимость к иному мировоззрению, образу жизни, поведению и обычаям. Сегодня проблема формирования и проявления толерантности и терпимости (как ее неотъемлемой составляющей) стоит особенно остро. Тому есть ряд причин:

- заметное расслоение мировой цивилизации по экономическим, социальным, культурно-образовательным и другим признакам;

- активное развитие религиозного экстремизма;

- резкое обострение межнациональных отношений, вызванных локальными войнами и появлением беженцев.

Проблема проявления толерантности и терпимости волновала человечество с давних пор. Уже во времена Античности концепция терпимости начала находить отражение в многочисленных трудах философов и религиозных деятелей. У ряда древнегреческих мыслителей (Сократ, Платон и др.) терпимость связывается с интеллектуальным аскетизмом и определяется как «предпосылка духовного и социального сплочения людей». Аристотель, толкующий основную добродетель людей как «середину», как «нечто среднее между добром и злом, между плохим и хорошим; между моральным и аморальным», под терпимостью понимает «возможность равноценного существования вещей, людей» [1. С. 132].

Иные представления о терпимости мы находим в патристике духовнорелигиозных лидеров христианства II-VIII вв. Так, в трактате «О терпимости» Тертуллиана она определена как божественное начало, выражающее смирение и аскетизм (ограничение или подавление чувств, желаний), переплетающееся с верой.

Христианская концепция терпимости содержится в Нагорной проповеди, утверждающей равенство всех перед Божественным Законом. Одновременно 
она становится этическим принципом терпеливого послушания, основанного на любви, смирении, всепрощении.

Исследователь христианской философии М.Б. Хомяков считает, что у римских авторов Цельса, Цицерона и др. понятие «tolerantia» встречается крайне редко и обозначает акт выдержки, воли. Чаще всего ими употребляется понятие «раtientia» (от лат. «patior»- терпеть, страдать), имеющее отношение к терпению боли, тягот. Как полагают исследователи этого вопроса, здесь корнем толерантности выступают храбрость (fortitudo), перенесение тягот (perpessio) и терпимость (tolerantia).

По мнению Н.К. Рериха, терпимость приобретается путем воспитания в себе терпения, сдерживания раздражительности, а также путем изжития личностных страхов и эгоцентризма. Особое внимание он обращает на необходимость и важность культивирования человеком в себе любви к ближнему. Испытание терпением, как полагает Н.К. Рерих, есть одно из высоких испытаний [2. С. 89].

В стоицизме, одном из направлений античной философии, понятие толерантности усиливается - это связано с общим понятием идеала мудреца. Примечательно, что толерантность для стоиков свидетельствует об отрешении и решительном отказе мудреца от мира. В частности, римский писатель и историк Кассиодор именует терпение (patientia) как «подругу мудрых»; архиепископ Исидор Севильский терпимость относит к душе, терпение к телу. Важнейший постулат стоицизма - «Все люди граждане космоса как мирового государства», а значит, они равны друг перед другом.

Августин Блаженный, христианский теолог Средневековья, терпение связывает с грехопадением человека (причиной этих дурных обстоятельств), что уничтожается искуплением, он называет терпение мучительным самосозидательным борением с собой.

Фома Аквинский, выдающийся мыслитель и теолог ХІІІ в., говорит в своих трудах о терпимости в значении претерпевания страстей и зла. Можно сказать, что понятие терпимости сводилось прежде всего к моральной добродетели, к терпеливому отношению к догматам, обрядам и верованиям нехристианского или даже еретического толка (чтобы избежать столкновений).

Особый (религиозный) взгляд на терпимость мы находим и у английского философа-материалиста XVII в. Дж. Локка. В частности, в его работе «Послание о веротерпимости» разрабатывается концепция о религиозной веротерпимости. Эта точка зрения была уместной и актуальной для того времени, так как общество сотрясали многочисленные вспышки религиозных конфликтов между католиками и протестантами [3. С. 298].

Как видим, в развитом Средневековье понятия «терпение» и «терпимость» становятся родственными или равнозначными страданию. Но уже совершенно иной взгляд на категорию «терпимость» складывается в период Нового времени. Здесь доминирующая роль в ее разработке принадлежит уже не столько теологам и религиозным деятелям, сколько философам. И они предлагают иной взгляд, существенно отличающийся от религиозного понимания и трактовки терпимости.

Философия Нового времени определяет терпимость как некий категорический нравственный императив, позволяющий понимать терпимость как 
общечеловеческую нравственную ценность субъекта. И эта ценность зависит от его самоопределения и его жизненной позиции. Главным условием выступает здесь наличие равенства прав, уважения других и другими.

Начало разработки проблемы терпимости положено Тихоном Задонским в труде «Сокровище духовное, от мира собираемое». Им предлагается определение терпимости как всепрощения и отсутствия мести. Просветитель начала XIX в. А.П. Куницын, размышляя о проблемах веры, свободы мысли, религиозных догматах, писал, что терпимость есть самое надежное оружие для поражения расколов, поскольку она дает людям время поразмыслить о догматах веры.

В конце XIX - начале XX в. концепция терпимости получает развитие в трудах русских философов, писателей и мыслителей Л.Н. Толстого, Н.К. Рериха, П.А. Сорокина, М. Тареева, С.Н. Трубецкого. Все они так или иначе размышляли о веротерпимости в своих трудах. Наиболее последовательно, на наш взгляд, проблематика терпимости раскрыта у Л.Н. Толстого в его концепции о непротивлении злу насилием. Чтобы быть готовым к непротивлению злу, считал он, человек должен побороть гордыню, стремление выделиться, быть лучше других, воспитать в себе терпимость. Терпимость отождествляется Л.Н. Толстым со смирением. Именно в смирении, смиренности видится ему спасение человека и человечества.

Данная позиция близка идеям социолога П.А. Сорокина, который все поступки человека делит на «делание чего-нибудь» или «неделание». «Неделание», в свою очередь, распадается еще на две категории: акты терпения (акты активные, состоящие именно в терпении ряда воздействий, исходящих от других людей; не сопротивление, а терпение нужно и требуется, чтобы победить зло; не пассивное воздержание, а любовное действенное терпение) и акты воздержания (акты пассивные, состоящие в воздержании от какихлибо действий).

Помимо этого, П.А. Сорокин выделяет два типа терпения. Предметное терпение - это терпение ряда действий, отнимающих у кого-либо то или иное «благо»: супруга, детей, деньги, дом, землю, скот, имущество, драгоценности и т.п. Беспредметное терпение - это терпение, например, издевательства, оскорбления, насилия, истязания, заключения в тюрьме и т.д.

В целом можно говорить о том, что П.А. Сорокиным в той или иной форме провозглашаются этические постулаты альтруистичного человечества. Среди них - гуманное отношение к преступникам, приоритет перевоспитания (а не наказания), терпимость к инакомыслию, следование идеям бескорыстной, созидательной любви и др.

Огромный вклад в разработку проблемы терпимости внес Альберт Швейцер, немецко-французский мыслитель, протестантский теолог. Исходный принцип его мировоззрения - «преклонение перед жизнью» как основой нравственного обновления человечества. Его этическое учение «Благоговение перед жизнью» иначе называют этикой смирения. В основе этики смирения лежит миропонимание как уважение жизни - своей и другого человека, ближнего или дальнего. По своей сути этическое учение А. Швейцера это жизнеутверждение, что жизнь - это высшая ценность. И к ней нужно 
относиться как к высшей ценности. Вне всякого сомнения, это крайне важная и своевременная для сегодняшнего времени мысль.

По мнению философа В.С. Соловьева, терпеливость можно определить как страдательную сторону великодушия или духовного мужества [4. С. 145]. Мужество, невозмутимость, терпеливость, великодушие в понимании В.С. Соловьева являются рядоположенными понятиями, отражающими силу духа человека.

Терпимость философ определяет как вариант терпеливости, которая ассоциируется у него с допущением чужой свободы. И это свойство, и отношение не есть само по себе ни добродетель, ни порок. Оно может быть в различных ситуациях и тем и другим - смотря по предмету. Например, торжествующее злодеяние сильного над слабым не должно быть терпимым. И потому «терпимость» к нему не добродетельна, а безнравственна.

Главным же образом, подчеркивает философ В.С. Соловьев, смотреть нужно на внутренние мотивы. А таковыми могут быть здесь и великодушие, и малодушие, и уважение к их благу, и глубокая уверенность в побеждающей силе высшей истины, и равнодушие к этой истине» [5. С. 119].

Немецкий мыслитель Фридрих Вильгельм Ницше рассматривает толерантность как творческий, интенсивный поиск свободы как способности человека действовать в соответствии со своими интересами и целями, опираясь на объективную необходимость. Переход от терпения и нетерпения представляет напряженную борьбу с привычными стереотипами. Например, с торопливостью, с говорливостью. То есть показатели терпения, по Ф. Ницше, - это медлительность, независимость от времени, внутреннее спокойствие, сдержанность, молчаливость и другие важные качества личности [6. С. 87].

Сегодня мы живем в мире, где взаимодействуют различные национальные культуры, народы и религии и где банальное невежество может стать причиной деструктивных явлений, в числе которых религиозная дискриминация, национализм, расизм и др. К сожалению, мы все вынуждены признать, что высочайшие завоевания научно-технического прогресса, достигнутого человечеством в самых различных областях, не являются гарантией высокой толерантной культуры, основанной на взаимопонимании и терпимости, на взаимном межкультурном корректном общении.

Особенно сильное воздействие на человеческое сознание оказывают различные формы конфронтации на этнической почве. И как результат - нарастание в обществе интолерантных, нередко достаточно агрессивных настроений с выраженным (или завуалированным) деструктивным компонентом, неприязнью к другим.

Поскольку межличностная толерантность предполагает готовность воспринимать «другого» как уникальную личность, наделенную собственной индивидуальностью и особым миропониманием, то данный процесс не представляется возможным без определенной внутренней работы над собой, без воспитания в себе внутренней и внешней культуры толерантного межкоммуникативного поведения в социокультурной среде. В нынешнее время толерантность надо понимать как уважение, правильное понимание и принятие 
других культур, взглядов, способов самовыражения и проявления личностной индивидуальности.

Что касается самой сущности толерантной культуры, то она заключается в том, что, во-первых, гарантирует права и важность индивидуальных свобод человека, которые существуют в мире вместе с различиями в базовых ценностях. Во-вторых, толерантная культура должна стать нормой жизни современного общества. А сегодня мы пока видим то, как отсутствие толерантной культуры у отдельных групп молодежи или отдельных личностей ведет к столкновениям на этнической почве.

В-третьих, толерантность имеет большое значение в создании:

- cреды взаимопонимания, уважения, принятия богатого многообразия культур, приятия в социуме форм самовыражения и способов проявления человеческой индивидуальности,

- равных и близких отношений между людьми, имеющими серьезные различия в культуре, религии, обычаях.

Современный глобальный кризис культуры и человека преодолим лишь при условии, что за основу развития того или иного сообщества будет взят духовный потенциал его культуры. По-видимому, пришло время, когда все мы (и каждый в отдельности) должны научиться не только слушать, но и слышать симфонию голосов чужой совести, другой религии, иной культуры. Современное сложное состояние мира взывает к тому, чтобы люди и культуры народов объединились в едином порыве навстречу толерантному взаимодействию, чтобы люди разных рас, живущие на разных континентах и говорящие на разных языках, стремились понимать друг друга.

На сегодняшний день объективные процессы интеграции стран и народов мира, разнообразие их многонациональных культур расширяют пространство процессов познания и межкультурного общения. Тем самым они ориентируют мировое сообщество на утверждение толерантной модели как парадигмы XXI столетия, которая была бы направлена на организацию комплиментарного взаимодействия людей, на выявление различных форм взаимодействия, общения и взаимопонимания носителей разных культур и форм самосознания.

«Быть толерантным» - это отнюдь не означает «всеядности» в вопросах межкультурного общения и взаимосуществования, не подразумевает уступок и снисхождения к чужому мнению, а также навязывания своих убеждений и точек зрения другим людям. Разделять и принимать толерантную модель поведения и самовыражения - значит осознавать различия и самодостаточность «другого», корректно относиться к иным суждениям людей как к своим собственным, невзирая на те или иные этнические, национальные и иные предпочтения.

Сегодня пристальное внимание к проблеме толерантности является одним из важнейших предпосылок снижения напряженности в межкультурной многонациональной окружающей среде. Умение принять иную точку зрения становится одним из критериев положительной оценки человека, обладающего устойчивыми социальными и нравственными убеждениями, способного усваивать и перерабатывать новую информацию, способного к социальной адап- 
тации и социальному творчеству. Формирование толерантности - это одно из условий успешного развития современного общества.

Следует подчеркнуть, что, как правило, развитие толерантности тесно связано с когнитивным развитием человека, с осмыслением его поступков и реакций. В процессе нравственного становления каждый человек проходит сложный путь. Путь от эгоцентрического отношения к окружающему, при котором любой поступок оценивается как хороший или плохой в соответствии с усвоенными правилами, до более гибкой позиции, когда в своих суждениях о других людях или ситуациях человек начинает придавать все большее значение личностным критериям. То есть критериям, сформированным на базе осмысления собственного опыта [7. С. 39-58].

Решение проблемы формирования толерантности в учебных заведениях страны приобретает особую значимость, так как у студентов в последние годы наряду с высоким интеллектом, широким кругозором и духовными запросами порой развивается чувство своей исключительности, излишней самоуверенности, стремление к самоутверждению своей независимости [8. С. 100-107]. Развитие общественных отношений выдвинуло на передний план вопросы разностороннего развития личности. Следовательно, потребовало осмысления разнообразных факторов в их совокупности и взаимодействии, влияющих на формирование человека.

Социально-адаптивная функция толерантности включает в себя активное приспособление человека к изменившейся среде на основе осознанного формирования новых способов своего поведения, гармонизирующих взаимоотношения с окружающими; сюда же включены и оптимизация взаимоотношений индивида с группой, сближение их целевых и ценностных ориентаций, вхождение индивида в ролевую структуру группы, равно как и непосредственный процесс (и результат) освоения человеком новых для него социальных ролей и позиций, значимых для него самого и социума в целом [9. С. 56].

Иначе говоря, сформированная у человека толерантность позволяет ему легко вступать в коммуникативные связи с другими людьми, а этически грамотная позиция в общении делает человека толерантным [10. С. 33].

\section{Лumepamypa}

1. Большой энциклопедический словарь. М. : МФЦП, 2002. С. 132.

2. Рерих Н. Сочинения. М., 1998. С. 89.

3. Аквинский Ф. Сочинения. М., 1983. С. 298.

4. Антология мировой политической мысли : в 5 т.: Политическая мысль в России: Вторая половина ХІХ-XX в. / руководитель проекта Г.Ю. Семигин и др. М. : Мысль, 1997. Т. 4. С. 145.

5. Соловьев В.С. Философская публицистика. М., 1989. С. 119.

6. Толерантность в студенческой среде: Теория и практика. СПб., 2012. С. 8.

7. Гукаленко О.В. Воспитание в современной России / О.В. Гукаленко, А.Я. Данилюк // Вестн. Моск. ун-та. 2008. Сер. 20, № 1. Январь - март. С. 39-58.

8. Воробьев Н.Е. Мультикультурная подготовка учителя в США / Н.Е. Воробьев, И.С. Бессарабова // Педагогика. 2008. № 4. С. 100-107.

9. Лазарева Е.С. Формирование этнической толерантности студенческой молодежи в процессе обучения в вузе // Динамика культурных процессов в современной России : материалы Общерос. науч. конф., 2012 г. / отв. ред. Г.А. Романова. Смоленск, 2012. С. 56.

10. Толерантность - духовно-нравственная основа единого образовательного пространства. Москва; Воронеж : Изд-во АПСН, 2003. С. 33. 
Demirhan Suleyman Tomsk State University (Tomsk, Russian Federation).

E-mail: rrpin8@mail.ru

Tomsk State University Journal of Cultural Studies and Art History, 2017. № 27. 26-33 pp. DOI: $10.17223 / 22220836 / 27 / 3$

THE MAIN CONCEPTUAL APPROACHES TO THE DEVELOPMENT OF TOLERANCE IN INTERCULTURAL ENVIRONMENT

Key words: tolerance, patience, culture, point of view, multinational environment.

The article studies the notion of "tolerance" in the human environment, discusses its stages of formation and development: the value of "humility", "austerity", "tolerance" to "respect the right understanding and acceptance of other cultures, attitudes, modes of expression and manifestation of personal identity ". To any modern society has successfully developed and that such global issues as religious discrimination, nationalism, racism did not circulate widely in the world, it is important to the ability of each and everyone to adapt to a rapidly changing social environment, exercise tolerance. In the future world society will move to new variants and models of general culture of tolerance.

The relevance to the treatment of tolerance problem and its philosophical reflection does not require justification verbose. Indeed, nothing is more sought after and requested in the modern world than the tolerant relations between people, but there is nothing more scarce and, on the other hand, are less well understood than that, what are the essential characteristics of tolerant relations between whom and whom they can and in what way reach. The concept of tolerance is more than three hundred years, and the first manifestation of it as a social and cultural reality appear much earlier and refer back to the days of antiquity, which makes the study of how the idea of tolerance and its historical incarnations relevant. The urgency is given a special condition of modernity: postmodernism in culture and globalization processes in the world, leading to an unprecedented pluralism of all aspects of life. One of the most important characteristics of this cultural condition is the destruction or erosion of the concept of standards. This determines the special relevance of any design concepts of tolerance, particularly given projected normative discourse.

Despite the fact that intolerance in the modern world is one of the general problems and the types of it diverse (from acts of terrorism, xenophobia, ethnic and national conflicts, discrimination against minorities, particularly refugees and immigrants), it must be stressed that it is tolerance as a later term in the history of human culture (rather than intolerance) is located in the heart of this study, since it raises the questions on how to overcome such or redemption in the process of cultural genesis of such characteristics of the individual and society. In other words, the question of the dialectic of intolerance and tolerance. Historical and logical sequence of this process sharpened on topical problems of tolerance in the contemporary socio-cultural situation in three main contexts: 1) formation of tolerant relations with the subsequent registration and revision of the concept of tolerance in society; 2) the problem of tolerance in modern society, and 3) the impact of globalization and its impact on the phenomenon of tolerance.

\section{References}

1. Solodovnokov, S.Yu. (ed.) (2002) Bol'shoy entsiklopedicheskiy slovar' [Great Encyclopedic Dictionary]. Moscow: MFTsP.

2. Rerikh, N. (1998) Sochineniya [Works]. Moscow: [s.n.].

3. Saint Thomas Aquinas. (1983) Sochineniya [Works]. Moscow: [s.n.].

4. Semigin, G.Yu. et al. (1997) Antologiya mirovoy politicheskoy mysli: $v 5 t$. [Anthology of World Political Thought]. Vol. 4. Moscow: Mysl'.

5. Soloviev, V.S. (1989) Filosofskaya publitsistika [Philosophical Publicism]. Moscow: Pravda.

6. Anon. (2012) Tolerantnost'v studencheskoy srede: Teoriya i praktika [Tolerance in the Student Environment: Theory and Practice]. St. Petersburg: [s.n.].

7. Gukalenko, O.V. \& Danilyuk, A.Ya. (2008) Vospitanie v sovremennoy Rossii [Education in modern Russia]. Vestnik Moskovskogo universiteta - Moscow University Bulletin. Series 20. Pedagogical Education. 20(1). pp. 39-58.

8. Vorobiev, N.E. \& Bessarabova, I.S. (2008) Mul'tikul'turnaya podgotovka uchitelya v SShA [Multicultural teacher training in the USA]. Pedagogika. 4. pp. 100-107. 
9. Lazareva, E.S. (2012) [Formation of ethnic tolerance of student youth during their studies in the university]. Dinamika kul'turnykh protsessov v sovremennoy Rossii [Dynamics of Cultural Processes in Modern Russia]. Proc. of the All Russian Conference. Smolensk. (In Russian).

10. Turbovskiy, Ya.S. (2003) Tolerantnost' - dukhovno-nravstvennaya osnova edinogo obrazovatel'nogo prostranstva [Tolerance is the Spiritual and Moral Basis of a Single Educational Space]. Moscow; Voronezh: APSN. 